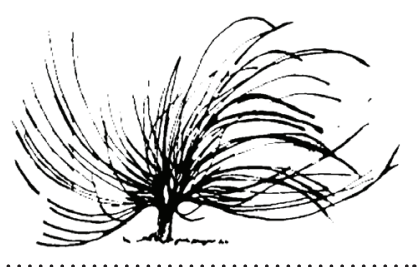

\title{
Justicia social para una vivencia afectiva y sexual en Costa Rica
}

\author{
Manuel Arturo Fallas Vargas ${ }^{1}$ \\ Universidad Nacional \\ Heredia, Costa Rica \\ manuel.fallas.vargas@una.cr \\ Nancy Torres Victoria ${ }^{3}$ \\ Universidad Nacional \\ Heredia, Costa Rica \\ nancy.torres.victoria@una.cr
}

\author{
José Antonio García Martínez $z^{2}$ \\ Universidad Nacional \\ Heredia, Costa Rica \\ jose.garcia.martinez@una.cr \\ Adriana Romero Hernández ${ }^{4}$ \\ Universidad Nacional \\ Heredia, Costa Rica \\ adrianarom@hotmail.com
}

\begin{abstract}
Resumen
En el presente trabajo se reflexiona sobre la justicia social y las sexualidades, desde un enfoque que responde a un modelo educativo que se centra en el respeto de las diferentes biografias sexuales, partiendo de un principio donde la carencia de justicia social implica una merma en la vivencia afectiva y sexual de las personas. Se sustenta en una revisión y reflexión en torno a la teoría y a la realidad costarricense
\end{abstract}

\section{$\circledast(\mathbb{2} \otimes(\Theta$}

Recibido: 1 de setiembre de 2015_Aprobado: 25 de abril de 2016

1 Doctor en Sexualidad y Relaciones Interpersonales por la Universidad de Salamanca, Magíster en Psicopedagogía y Licenciado en Ciencias de la Educación con énfasis en Orientación. Actualmente ejerce como docente e investigador en la División de Educación para el Trabajo (CIDE) de la Universidad Nacional, Costa Rica.

2 Máster en Educación y Tecnologías con énfasis en Investigación en la Universidad Abierta de Cataluña. Ejerce como docente e investigador en la División de Educación para el Trabajo (CIDE) de la Universidad Nacional, Costa Rica.

3 Doctora en Educación con especialidad en Mediación Pedagógica. Historiadora y curriculista, ejerce como académica e investigadora en la División de Educación Rural y la División de Educación para el trabajo (CIDE) de la Universidad Nacional, Costa Rica.

4 Licenciada en Orientación; Bachiller en Sociología. Ejerce como académica de la División de Educación para el Trabajo (CIDE) de la Universidad Nacional, Costa Rica. 
reflejada en diferentes medios de comunicación actuales. Igualmente se sugiere una serie de buenas prácticas para el fortalecimiento de la justicia social desde esta perspectiva.

Palabras clave: Justicia social, sexualidad, educación sexual, derechos humanos, diversidad.

\begin{abstract}
In this article, the authors meditate on social justice, sexuality and the link between this these two concepts towards a more inclusive and respectful society. Our approach responds to an educational model centered in the respect of the different types of sexual biographies, starting from the principle that the lack of social justice implies a decrease in the emotional and sexual experience of people. This paper is based on a review and consideration around Costa Rican theory and reality as seen in the current media. There is also a suggestion of a series of good practices and some conclusions for the strengthening of social justice and ergo an emotional and sexual well-being of people.
\end{abstract}

Keywords: social justice, sexuality, sexual education, human rights, diversity

\title{
Introducción
}

Para nadie es un secreto que la democracia, la justicia social y, por tanto, la libertad para ejercerla no es un concepto que se aprende en abstracto, sino se debe vivenciar; es un concepto que requiere dejar de ser sustantivo para convertirse en verbo; en otras palabras, la justicia social es una realidad que se construye día tras día en una sociedad que se considera democrática, desde la cotidianidad de cada persona, pueblo o nación.

La justicia social de un país debe regirse y evaluarse por sus logros presentes y futuros en el avance de igualdad de oportunidades de sus habitantes, alcances que redundan en las diversas facetas o necesidades humanas que inciden indudablemente en la calidad de vida del colectivo ciudadano; dentro de esta, la sexualidad y su vivencia 
saludable retoman un valor fundamental en una sociedad que se visualiza como promotora de justicia social.

\section{Justicia social y sexualidad}

Es importante identificar algunos elementos conceptuales que permitan fundamentar nuestra reflexión relacionada con la justicia social, la sexualidad y vivencia efectiva. El primero de ellos es el acercamiento al concepto de justicia social, con la salvedad, de que el mismo concepto puede presentar diversidad de connotaciones, pues es un término vinculado con la política, lo social y lo cultural, entre otros. Además, conlleva sentimientos, deseos, esperanzas, afanes y anhelos por contar con una sociedad más desarrollada en materia de equidad y justicia social.

A su vez, dicho concepto incluye la idea de dinámica de transformación-evolución, ya que una sociedad saludable, a criterio de quienes escriben, siempre apuesta por un cambio en pro de mejores condiciones $\mathrm{y}$ en respuesta a las nuevas demandas.

Aunado a lo anterior, la justicia social se basa en:

... [la] igualdad de derechos para todas las personas y la posibilidad para todos los seres humanos, sin discriminación, de beneficiarse del progreso económico y social en todo el mundo. La promoción de la justicia social significa más que aumentar los ingresos y crear empleos. Significa también derechos, dignidad y voz para las mujeres y hombres (...), así como emancipación económica, social y política. (Organización Internacional del Trabajo [OIT], 2011, párr. 1)

Ampliando la conceptualización expuesta, Murillo, Román y Hernández (2011) señalan que, si bien este concepto tiene un carácter distributivo, no se queda solo ahí, va más allá, hace referencia a tres acepciones, una relacionada con la demanda de igualdad entre todas las personas, aludiendo a "justicia como equidad"; hace alusión a los "bienes primarios" en los que se encuentran los derechos y las libertades básicas, la remuneración y la riqueza, lo relacionado con los puestos públicos, la responsabilidades, entre otros. Según Murillo et al. (2011, 
citando a Sen, 1997), se visualiza la justicia social y sus fundamentos, en la "... búsqueda y aseguramiento de la libertad de las personas para elegir distintos modos de vivir" (p.10).

La segunda acepción del término justicia social es el de reconocimiento, entendido como justicia relacional o cultural, donde se toma como "... la ausencia de dominación cultural..." (Fraser, citado por Murillo et al., 2011, p. 10). Esto hace alusión a una visibilidad de las necesidades e identidades de los mal llamados "grupos minoritarios", ya que cuando hablamos de derechos, equidad y justicia, estamos hablando de personas y no de un número, donde lo cuantitativo nunca debe privar a lo humano ni a su condición de humanidad, ya sea por etnia, género, orientación del deseo sexual, cultura, entre otras, señalando por tales, diversas formas de injusticia y opresión (sexismo, heterosexismo, machismo, entre otras).

La tercera acepción al término de justicia social es el asumido como participación. Desde esta perspectiva, no puede estar divorciada de la participación, ya que esta "... implica la promoción del acceso y la equidad para asegurar la plena participación en la vida social" (Murillo, et al., 2011, p. 10). Estos alcances nos sitúan frente a toda persona que es excluida e invisibilizada por su procedencia, sexo, construcción de género, discapacidad, educación, orientación del deseo sexual, identidad, edad, características personales, entre otras.

$\mathrm{Al}$ reconocer estos alcances de la definición de justicia social (sin omitir la existencia de otros no mencionados), vemos que se reafirma la idea de visualizarla, como una construcción o un proceso continuo, que va más allá de factores materiales y distributivos, ya que el concepto "involucra no solamente cuestiones materiales, dinero, inmuebles, etc., también cae en su ámbito, la honra, la alegría, la espiritualidad" (G. Steele, comunicación personal, 12 de febrero, 2015). Esto obliga al Estado, las casas formadoras de educación superior y la sociedad en general, a promover espacios de crecimiento, para conseguir que la justicia social logre satisfacer todas aquellas nuevas demandas personales y sociales del actual siglo en miras a un desarrollo humano sostenible, entendido como:

Un proceso de cambio progresivo en la calidad de vida del ser humano, que lo coloca como centro y sujeto primordial del desarrollo. Es aquel que se construye a partir del protagonismo real de las personas (familias, niños y niñas, productores, organizaciones e 
instituciones locales y fomenta un tipo de crecimiento económico con equidad social, así como la transformación de los métodos de producción y de los patrones de consumo que se sustentan en el equilibrio ecológico y dan soporte a las formas de vida de acuerdo a los valores de las personas según su espacio. (Cruz, s. f., párr. 1)

No queda este proceso solo en una práctica inacabada, pero con carácter oficial y universal. Por otro lado, el sector político y las fuerzas vivas de una nación tienen la obligación de velar por las condiciones necesarias para que la vivencia efectiva de dicha justicia social se convierta en un deber hacer, donde debe estar libre de estereotipos, conocimientos sesgados y juicios morales fundamentados en unas creencias personalistas, que podrían no responder a la realidad latente y cotidiana de un sector o de la totalidad de la población.

\section{Sexualidad}

La sexualidad humana es definida como un aspecto central que la persona vivencia y construye durante toda su vida y concretamente:

Se refiere a una dimensión fundamental del hecho de ser humano. Basada en el sexo, incluye el género, identidades de sexo y género, orientación sexual, erotismo, vínculo emocional, amor, y reproducción. Se experimenta o se expresa en forma de pensamientos, fantasías, deseos, creencias, actitudes, valores, actividades, prácticas, roles y relaciones. La sexualidad es el resultado de la interacción de factores biológicos, psicológicos, socioeconómicos, culturales, éticos y religiosos o espirituales. Si bien la sexualidad puede abarcar todos estos aspectos, no es necesario que se experimenten ni se expresen todos. En resumen, la sexualidad se practica y se expresa en todo lo que somos, sentimos, pensamos y hacemos. (OPS-OMS, 2000, p. 8)

La riqueza de contar con una visión multidimensional de la sexualidad, fructífera en múltiples funciones y expresiones, le permite a la persona tener una amplia gama de posibilidades de acción que respondan a su propia edificación de sexualidad y su vivencia efectiva y responsable. De manera que es en cada persona donde "la sexualidad 
existe como energía inmanente de crecimiento y desarrollo pero que no se queda en el individuo, sino que le impulsa a establecer relaciones con las demás personas y el universo como tal" (G. Steele, comunicación personal, 12 de febrero, 2015). Como puede observarse, el concepto de sexualidad coincide con el de justicia social, en su carácter de construcción, de desarrollo, constante dinamismo y correspondencia con lo humano y su diversidad en sí o de la otra persona.

\section{¿Qué relación existe entre justicia social y sexualidad?}

Tomando en consideración lo expuesto en los párrafos anteriores, el lector o lectora seguro que ha ido hilando las relaciones existentes entre estos dos conceptos, no solo a nivel de ideas conceptuales, sino en el impacto real (muchas veces no el más grato) de la vivencia cotidiana que enfrentan las personas a nivel personal o social en cuanto a la sexualidad en Costa Rica.

Para fortalecer dicha reflexión, se nombran algunos ejemplos, los cuales permitirán reconocer e identificar, desde la realidad del otro individuo (o incluso de la suya propia), la necesidad de una vivencia de la sexualidad y una educación sexual desde un marco de justicia social que responda a una Costa Rica que se sustenta en una sociedad diversa y, por tal, plural en la convivencia y, en este en particular, la pluralidad afectiva y sexual. Entre dichos ejemplos tomados a lo largo de este último quinquenio, podemos retomar:

-El caso de la disparidad relacionada con los ingresos entre mujeres y hombres, donde el diario La Nación (Mata, 2010, párr. 1), señala que en promedio "las mujeres ganan un $26 \%$ menos que los varones"; que una “... trabajadora recibe, en promedio, $\notin 74$ por cada $₫ 100$ que gana un hombre al realizar las mismas labores". La noticia menciona un estudio sobre Tendencias recientes de la inserción femenina en el mercado laboral de Costa Rica, elaborado por el Estado de la Nación y el Instituto Nacional de la Mujer (INAMU). La investigación señala que la “...brecha de género en los ingresos obedecen a la discriminación constante que sufren las mujeres, pues se considera que sus sueldos son secundarios para las economías de los hogares" (Mata, 2010, párr. 3). Este documento continua marcando que "...otra causa del 
incremento de la disparidad salarial es la carencia de una política de empleo con enfoque de género, que resguarde los derechos de las trabajadoras (Mata, 2010, párr. 4).

-Otra situación relacionada con la mujer, pero esta vez haciendo énfasis con embarazo en adolescentes se publica en La Nación-Aldea Global, plantea la situación que tienen las niñas o adolescentes embarazadas en nuestro país, y hace un llamado de atención, ya que los múltiples juicios de valor que genera la situación "...urgen a Costa Rica a tomar un nuevo rumbo en la forma de educar sexualmente a la población sobre métodos de prevención, respeto de los derechos y atención integral a la joven embarazada" (Barrantes, 2013, párr. 2). Este medio de comunicación acota, según la Señora Rossy Méndez (Presidenta del Consejo Interinstitucional de Atención a la Madre Adolescente, CIAMA), que la educación brindada, “....es insuficiente y está llena de mitos que tienen que ver con las personas responsables de transmitir la información. No podemos pretender que los jóvenes estén educados, si hay un rezago generacional sobre la forma en que se habla sobre sexualidad" (Barrantes, 2013, párr. 4).

Por otro lado, y complementado la información de esta noticia, agrega que cuando existe abuso y como tal un embarazo "...se suma el hecho de que la sociedad aún maneja un discurso machista, pues la mujer se convierte en la responsable de su situación y el hombre es un fugitivo invisibilizado" (Barrantes, 2013, párr. 5).

Otro aspecto generado de la entrevista publicada por dicho medio de comunicación, que incide en el factor educación y la exclusión económica-social, es que pese a los esfuerzos por parte del sistema educativo para evitar el abandono escolar, "...la difícil situación económica obliga a muchas a abandonar las aulas", lo cual genera aún mayor posibilidades de que la joven no logre conllevar su nueva condición de madre adolescente, sin mencionar su desarrollo educativo (y dentro de lo educativo, la educación sexual) y profesional (Barrantes, 2013, párr. 7).

Otro hecho, desde la perspectiva de quienes escriben este documento, que se relaciona con la justicia social y sexualidad tiene que ver con la ambigua posición por parte del Gobierno y la escasa atención que la Asamblea Legislativa de Costa Rica, con respecto al Proyecto de Ley de Sociedades de Convivencia. Al respecto, Soto (2013a) manifiesta que: 
Parece que los derechos patrimoniales de las parejas homosexuales, lesbianas y transexuales tendrán que esperar a que los diputados tengan el ánimo de enrumbarse en la discusión del proyecto de ley de sociedades de convivencia que regularía el tema y que quedó pendiente antes del receso legislativo. Los jefes de fracción de las bancadas explicaron que no es factible iniciar la discusión del proyecto porque no tiene un consenso y sería entrabar la discusión de otras propuestas. (párr. 1)

El mismo medio señala que el Gobierno "decidió desconvocar hoy el proyecto de Ley de Sociedades de Convivencia, que se encontraba en discusión en el Plenario" (Soto, 2013b), ya que dentro de los mismos integrantes de la Comisión Legislativa de los Derechos Humanos no se dio el consenso, por lo que se procede a la desestimación.

En relación con la población del colectivo homosexual y lésbico, otra situación donde se refleja un carácter de exclusión social, es lo expresado por el ahora exdiputado y expresidente de la Comisión de Derechos Humanos del Congreso, don Justo Orozco (Administración 2010-2014) y la exdefensora de los habitantes. Al preguntarle al diputado: ¿Qué haría usted en caso de tener un hijo o nieto homosexual?, su respuesta fue la siguiente. "Ya mis hijos son adultos y ya soy abuelo y están casados; con los nietos, que Dios me libre de eso" (La Nación, 2013, párr. 5). Vemos en dicha respuesta, cómo los intereses y creencias personales de un funcionario público interfieren en la claridad de solución de un tema de interés social para dicho colectivo. Igualmente, en dicha noticia se cristalizan las palabras de la exdefensora del pueblo Ofelia Taitelbaum, que reafirma la condición de exclusión y discriminación que sobrelleva una parte de la población costarricense al señalar que:

Nosotros tenemos muchos casos en la Defensoría, realmente lamentables: una pareja de lesbianas, en la que una enferma estaba de muerte, en las salas del San Juan de Dios, y no le dejaban entrar a su compañera, a visitarla, por no ser familia. La familia, que siempre la despreció, que siempre la marginó, resulta que le impedían a propósito la entrada; murió la mujer sin ver a su compañera de vida, y sus bienes gananciales, que los obtuvieron juntas mientras eran pareja, le quedaron a su familia que siempre la discriminó y siempre la hizo a un lado. (La Nación, 2013, párr. 5) 
Para finalizar estos ejemplos de la realidad y situaciones en el país, no se puede dejar de mencionar lo relacionado con la Ley para regular la fecundación in vitro, que por más de una década ha estado en el oscurantismo, a pesar de la sentencia de la Corte Interamericana de Derechos Humanos (CIDH), la cual ha obligando a Costa Rica al acatamiento. Esto, debido a que nuestra clase gobernante y política no logra mediar de forma oportuna y pertinente de acuerdo con la realidad de las parejas con imposibilidad de procrear. Pese al paso del tiempo y una nueva administración pública y asamblea legislativa (2014-2019), aún en Costa Rica no se logra dar respuesta a este derecho y cumplir con el fallo de la CIDH, incurriendo así no solamente en una violación de derechos, sino en sanciones económicas que pudieron haberse evitado, si existiera voluntad política y una actitud flexible, científica y no conservadora.

Estos ejemplos, y otros en diversos contextos, temáticas y formas, dejan claramente entrever que Costa Rica aún tiene mucha tarea pendiente a nivel del logro de equidad en cuanto a la justicia social para una vivencia afectiva y sexual saludable. No se pretende caer en la negación de los derechos ganados a nivel social-sexual, su protección y alcance, que la sociedad ha logrado tanto por las instituciones como por ONG, pero igualmente no se puede dar la tarea por satisfecha; aún queda demasiado por realizar. En relación con esto, surge un compromiso con la nueva gestión presidencial, que llega al poder con una consigna que pareciera ser más respetuosa de los derechos humanos y derechos sexuales, que ha dado pasos importantes como es la modificación del reglamento del Seguro de Salud en octubre del 2014, donde la Junta Directiva CCSS, reformó los artículos 10, 12 y 13, que se relacionan con la protección a través del beneficio familiar y que abrieron la posibilidad para el aseguramiento de parejas del mismo sexo.

Igualmente otro aspecto rescatable es la creación de un Decreto en el 2015 que respalda la capacitación al colectivo funcionario del Estado sobre la temática de derechos, así como para crear normativa que sancione la discriminación en torno a la diversidad de esta población y del público en general (Periódico oficial la Gaceta, 2015). Este hecho es de vital importancia, si se tiene en cuenta la necesidad de formación en la sociedad en general y, por ende, del personal funcionario gubernamental, el cual cumple un doble rol; por un lado, atendiendo las necesidades específicas de la población y, por otro, proyectando unas actitudes erotofílicas, que debieran ser la base del respeto a los derechos humanos y su diversidad afectiva y sexual. 
A pesar de estos logros, falta un mayor hacer por parte del actual Gobierno y Asamblea Legislativa, donde solo el tiempo demostrará si las palabras y la teoría se convierten en realidad, para lo que se requiere pasar de la teoría firmada en los marcos internacionales, convenciones, cartas, decretos, entre otras (Convención América de Derechos humanos, Código de Trabajo en Costa Rica y, normativa conexa), a la concreción real de los derechos humanos y, entre ellos, los derechos sexuales (Declaración de Valencia, 1977, ratificados en la Conferencia World Association for Sexology [Was] Hong Kong, 1999), en busca de una mayor y mejor equidad e igualad de oportunidades en la construcción y vivencia de la sexualidad, respetando la biografía sexual de cada persona que viva en esta sociedad.

Como vemos, las relaciones entre estos dos conceptos que se van construyendo, son complicadas, dinámicas y extensas. Al respecto, el doctor Félix López Sánchez, manifiesta que estas son muy amplias y complejas. "El fundamento de esta relación es que todas las sociedades regulan numerosos aspectos de la conducta sexual y las relaciones amorosas y esa regulación puede ser más o menos justa o, como ocurre en muchos casos, muy injusta" (F. López, comunicación personal, 15 de abril, 2015).

Este mismo investigador hace alusión a la regulación que el Estado y otros grupos ejercen sobre la definición y praxis de dichos conceptos, el cual señala que los “....poderes públicos y las ideología religiosas, políticas o sociales regulan la sexualidad por fines muy diversos y de forma muy diferente". Lo anterior queda expuesto con situaciones señaladas al iniciar este apartado, o bien basta entrar a los diversos foros que se desarrollan en las redes sociales en nuestro país, para descubrir el estado de insatisfacción social en cuanto al respeto de la diversidad y equidad de trato e igualdad de oportunidades. El doctor López resalta igualmente una serie de ejemplos o situaciones, donde se observa esta relación e implicaciones, entre ellos:

a. las leyes que regulan la vida de las familias y las parejas, por ejemplo, para asegurar lo más posible que los hijos e hijas sean legítimos, no sean abandonados, no se les maltrate (tampoco sexualmente). Esto ha llevado a las sociedades a favorecer las parejas más estables, etc.

b. las iglesias tienen una injerencia ideológica muy negativa de la sexualidad y reprimen toda sexualidad fuera del matrimonio heterosexual. 
c. el primer capitalismo y los gobiernos autoritarios, siguiendo la ideología religiosa -en Estados más o menos claramente confesionales- hacían lo posible por reprimir la sexualidad contribuyendo con ello a una sumisión mayor.

d. el moderno capitalismo y las democracias liberales avanzadas siguen regulando la sexualidad, pero han descubierto que el libre comercio de la sexualidad es un negocio más que, además, contribuye a que la gente se sienta más libre, cuando es víctima de claro diseño con dos valores básicos: trabajar para ganar dinero y consumir, en una rueda sin fin.

Por otra parte, es evidente que los valores sexuales y las conductas sexuales están estrechamente relacionados con la ideología de las clases dominantes, donde las clases altas son las más hipócritas (moral formal y moral real); mientras las clases bajas son las menos protegidas de los abusos sexuales, el acoso y otras formas de maltrato sexual.

La justicia social es particularmente injusta en el campo sexual porque ha perseguido a las minorías (homosexuales, transexuales, etc.), niega la sexualidad a las personas con discapacidad, no plantea adecuadamente la prevención de riesgos de la actividad sexual, deja desamparadas las mujeres, especialmente a las que se ven obligadas a prostituirse, etc. (F. López, comunicación personal, 15 de abril, 2013).

Como puede visualizarse, la relación entre la justicia social y la sexualidad no puede pasar inadvertida, ya que existe una conexión inseparable de interdependencia cuando estos dos conceptos toman vida, al adquirir rostro humano, en la cotidianidad de sus vidas y singularidades. No se puede lograr un desarrollo humano sostenible sin la recreación total de la sexualidad humana dentro de un marco de libertad y ética relacional (Fallas, 2010). Por tal razón, los esquemas tradicionales y lineales de instituciones e ideologías patriarcales deben dar paso a una respuesta desvinculada de las antiguas estructuras sociales fundamentadas en el patriarcado, el cual se alimenta de una sociedad hegemónica, no únicamente del Estado sino de toda persona. Esto se debe a que en el desarrollo humano estamos implicados todos los individuos, tenemos responsabilidad en la construcción de una sociedad cuya base es la pluralidad en la convivencia, donde el respeto a otras formas de vivir la sexualidad sea incorporado desde la educación para la convivencia en el respeto; donde uno de los valores de la educación sea el respeto a la 
diferencia, y donde esta sea igualmente vivida y expresada, sin señalamientos, no bajo una sombra, ni tampoco sustentada en conocimientos sesgados que no toman en cuenta la otredad (Soto, s. f.).

La sexualidad y su diversidad, desde la perspectiva de la justicia social, debe reconocerse sin ser polarizada o sin darle un carácter binario (mujer o hombre), propio de los procesos culturales tradicionales patriarcales, que han llevado a plantear que el rango de "normalidad" está sujeto a polos; por el contrario, debe plantearse con base en mapas (geografía sexual) de la sexualidad desde su multidimensionalidad.

La relación justicia social y sexualidad debe permitirnos reconocer un mapa de construcciones sociales de género que están en tránsito y en busca de ser reconocidas y respetadas, y que nuestro país debe realizar el esfuerzo en busca del desarrollo en la formulación de teorías que expliquen todo ese fenómeno, partiendo del derecho que tienen las personas de la construcción de su biografía sexual dentro de un marco de ética de las relaciones (López, 2005 y Fallas, 2010). Este aspecto es clave para el desarrollo humano, ya que la sociedad como sistema diverso y la diversidad en sí misma nutre la salud de dicho sistema social, como dirían algunos estudios, su ecosistema o ambiente (Benavides, 2008).

Unido a lo anterior y a manera de conclusión de este apartado, se comulga con lo señalado por el Doctor Steele, al manifestar que:

Es imposible hablar de justicia social y sobre todo de sexualidad en el vacío. Es indispensable considerar el ser humano como depositario activo de ambos conceptos. ... Es, en este ejercicio de dar y recibir, propio de cualquier relación nutritiva, que tiendo a pensar en que la justicia social y la sexualidad encuentran su enlace. Ambas involucran necesariamente la variable respeto. (G. Steele, comunicación personal, 12 de febrero, 2015)

Lo connotado nos permite un vistazo parcial de un panorama diverso, de relación entre la justicia social para el logro de una vivencia afectiva y sexual de calidad. Estas relaciones, sin duda, hacen énfasis en aspectos de equidad entre géneros e inclusive en evaluar la necesidad de incluir los géneros alternativos que no están contemplados oficialmente dentro de las prácticas sociales y educativas; en la asunción de la diversidad afectiva y sexual; en la libertad en la construcción de la propia biografía sexual; en la violencia y el comercio sexual. 
La posibilidad o no de un desarrollo humano sostenible que garantice el respeto a la sexualidad de las personas debe revisar los esquemas lineales y tradicionales en las estructuras sociales de nuestro país (derecho, ideología, instituciones, entre otras), que interrumpen el tránsito de la construcción de una sociedad plural en la convivencia afectiva y sexual, o bien, en la necesidad de una educación para la convivencia en el respeto de sectores de la sociedad, que se desmarcan de lo asumido por una sociedad que se ha regido y rige (a nuestro pesar aún) en el oscurantismo del patriarcado.

Definitivamente, necesitamos incorporar en nuestro sistema educativo (en todos los niveles) el aprendizaje vivencial de una educación que permita crear y fomentar un contexto cada vez más inclusivo con respeto a la justicia social dentro del marco de la sexualidad. De manera que exista, como señala Muijs et al. (citado por Murillo et al., 2010), inclusión social. La inclusión para la justicia social se puede entender como la promoción de la igualdad de oportunidades para todos los seres humanos dentro de la sociedad, sin importar sus antecedentes o sus circunstancias personales. Esto conlleva a un fuerte propósito de educación inclusiva: “...para la justicia social, debe ser el de eliminar todo indicio de exclusión, ya sea por la pertenencia a determinada clase social, etnia, religión, género, o bien por la orientación sexual, la lengua materna, la cultura de origen o la manifestación de ciertas habilidades" (Kugelmass, citado por Murillo et al., 2010, p. 170).

\section{¿Qué requiere una sociedad para el logro de una justicia social que promocione la vivencia efectiva de la sexualidad?}

Tomando en consideración lo señalado en apartados anteriores, y lo expuesto por varios teóricos y teóricas (López, 2005, Fallas-Vargas, 2010, entre otros u otras) y sin pretender señalar que son los únicos requerimientos, de forma general se describen en la tabla 1, algunos aspectos que deben ser abordados por la sociedad y la educación para fortalecer la justicia social y sus buenas prácticas en la vivencia afectiva y sexual. 
Tabla 1. Aspectos para el fortalecimiento de la justicia social y su vivencia afectiva y sexual

\begin{tabular}{|c|c|}
\hline Acciones & Descripción \\
\hline $\begin{array}{l}\text { Saber científico } \\
\text { de la comunidad } \\
\text { costarricense }\end{array}$ & $\begin{array}{l}\text { Se requiere que nuestro país y la sociedad, desarrollen o } \\
\text { adquieran conocimiento científico sobre la sexualidad. } \\
\text { Conocimientos caracterizados por estar libres de compromisos } \\
\text { de grupos conservadores y de sesgos científicos, ya que } \\
\text { en la medida en que un pueblo avance en su saber, se aleja } \\
\text { de aquellos tiempos del oscurantismo intelectual y de la } \\
\text { manipulación. } \\
\text { En la magnitud en que un pueblo o nación se esfuerce por } \\
\text { poseer un conocimiento real y objetivo, la justicia social estaría } \\
\text { construida y fortalecida con criterios y acciones pertinentes de } \\
\text { respeto a la diferencia y a la equidad entre los seres humanos } \\
\text { (políticos, docentes, líderes comunales, familia, etc.). }\end{array}$ \\
\hline $\begin{array}{l}\text { Necesidad de una } \\
\text { sociedad secular }\end{array}$ & $\begin{array}{l}\text { Se requiere que la sociedad costarricense se secularice, que } \\
\text { el país se convierta en un Estado no confesional. De manera } \\
\text { que el Estado, sus instituciones, organizaciones, educadores/ } \\
\text { as y profesionales en general, puedan actuar sin transmitir una } \\
\text { moral sexual religiosa, que de forma consciente o inconsciente } \\
\text { se vivencia. } \\
\text { Que las decisiones que inciden de una u otra manera en la } \\
\text { vida de las personas, y en este caso particular en la vivencia } \\
\text { sexual, no sea obstaculizada por la incidencia o creencia } \\
\text { particular de una persona o grupos conversadores, la justicia } \\
\text { social es sinónimo de igualdad de oportunidades, y en una } \\
\text { Costa Rica pluralista, donde cada uno de sus miembros tiene } \\
\text { derecho a vivir su vida afectiva y sexual de forma libre, pero } \\
\text { responsable. }\end{array}$ \\
\hline Libertades sociales & $\begin{array}{l}\text { Es necesario que en Costa Rica se fortalezca aún más las } \\
\text { libertades sociales básicas que se han alcanzado en las } \\
\text { diversas áreas, en este caso particular en el de la sexualidad } \\
\text { humana y su educación, pero que dichos derechos, sean cada } \\
\text { día objeto-verbo no solo en teoría, sino que se plasmen en las } \\
\text { realidades concretas del ciudadano y ciudadana. } \\
\text { Un elemento importante en el fortalecimiento de las libertades } \\
\text { sociales en el ámbito de la sexualidad es el aprendizaje de } \\
\text { actitudes tolerantes y erotofílicas hacia la sexualidad y } \\
\text { su educación. Este aspecto actitudinal es fundamental en } \\
\text { los seres humanos, ya que una persona quizá no goce en } \\
\text { determinando momento de un conocimiento amplio, pero si } \\
\text { tiene unas actitudes positivas hacia la sexualidad, esto incidirá } \\
\text { en su querer saber, sentir y hacer (aspectos cognitivo, afectivo } \\
\text { y conductual de las actitudes). }\end{array}$ \\
\hline
\end{tabular}




\begin{tabular}{|l|l|}
\hline \multicolumn{1}{|c|}{ Acciones } & \multicolumn{1}{|c|}{ Descripción } \\
\hline & $\begin{array}{l}\text { Costa Rica requiere de una educación con una perspectiva; } \\
\text { instituciones de calidad, justas, integradas socialmente, } \\
\text { organizadas y enfocadas para la formación y respeto de } \\
\text { la diversidad afectiva y sexual; donde las instituciones } \\
\text { educativas (escuelas, colegios, universidades) se conviertan } \\
\text { en “... espacios de socialización y formación académica, } \\
\text { cultural y ética en donde se entrega una educación capaz } \\
\text { de incorporar a una sociedad democrática posibilitando una }\end{array}$ \\
trayectoria y experiencia de inclusión igualitaria para todos. \\
Educación de calidad \\
justa e inclusiva \\
$\begin{array}{l}\text { Una escuela en donde todos aprenden, desarrollan y fortalecen } \\
\text { sus capacidades al máximo para poder concretar sus genuinos } \\
\text { y válidos proyectos de vida" (Murillo, et al., 2011, p.13). } \\
\text { Por tal, se requieren profesionales con un liderazgo } \\
\text { pedagógico en la promoción de la educación afectiva y } \\
\text { sexual, líderes promotores de la justicia social (Torres, Cerdas } \\
\text { y García, 2013), con miras para que el proceso de aprendizaje } \\
\text { y transformación de la persona contribuya a la supresión de } \\
\text { toda forma de injusticia social. }\end{array}$ \\
\hline
\end{tabular}

\section{¿Cuáles serían algunas prácticas desde la justicia social que permi- tan una vivencia afectiva y sexual de calidad?}

Sin el afán de mostrar pretensión y reconociendo que es un tema complejo, desde nuestro análisis de la realidad y contraste con la teoría, se espera dar posibles reflexiones que permitan al lector o lectora generar procesos de discusión y análisis de la cotidianidad. Y por qué no, incentivar a buscar "buenas prácticas" para fortalecer la creación de una cultura de respeto a la diversidad y de la diferencia (y su valor) dentro del mundo afectivo y sexual de la sexualidad.

Tomando en consideración los aportes de F. López (comunicación personal, 15 de abril 2015) al respecto, desde un enfoque positivo, así como la contribución de quienes escriben este documento, se consideran algunas "buenas prácticas":

a. Desde un plano internacional: que la Organización de Naciones Unidas (ONU) acepte la Declaración Universal de Derechos Sexuales promulgada en Valencia (España), y ratificada por la Conferencia Word Associaation for Sexology -WAS- (Declaración de Valencia 1977, ratificados en la Conferencia World Association 
for Sexology [Was] Hong Kong, 1999), la cual, según López (2013), “... aún no se consigue que la apruebe la ONU porque los países islámicos, las iglesias, etc., no la aceptan."

b. Se comparte con el autor antes citado la necesidad de constituir una legislación que ampare a la infancia de todas las formas de maltrato sexual. Incluye las mutilaciones, los matrimonios que enlazan niñas prepúberes con mayores, el abuso sexual a menores, la no aceptación de las personas transexuales, la no aceptación de las personas homosexuales, la no aceptación de los derechos sexuales de las personas con discapacidad, etc.

c. Unido a lo anterior, brindar esfuerzos por extender una educación inclusiva y respetuosa de la diferencia, una educación integral, con el modelo biográfico y profesional (López, 2005). Este modelo deja claramente una propuesta educativa, fundamentada en conocimientos científicos y donde se caracteriza el rol de la persona, de grupos profesionales, de la familia y de las leyes sociales que amparan a la población menor de edad y a las personas con discapacidad.

d. Crear mayores y mejores redes jurídicas y asistenciales que ayuden a las víctimas sexuales (de abusos, violaciones, acoso, etc.) a lograr obtener, de forma pronta y segura, una respuesta, no solo de atención legal, sino en los aspectos de prevención y de apoyo emocional.

e. Creación de una legislación para la persona adulta, que favorezca que estas:

Puedan organizar su vida sexual y amorosa con libertad (diferentes tipos de pareja y familia, derechos sexuales generalizados) y responsabilidad. Por ejemplo con derecho a vincularse y desvincularse, pero con la responsabilidad de no hacer daño a los hijos/as, etc. En definitiva, los seres humanos podemos tomar decisiones sobre nuestra vida sexual con un alto grado de libertad, nuestra sexualidad no está programada digitadamente, SINO EN EL “REINO DE LA LIBERTAD”. Y a esto es a lo que debemos ayudar: a que decidan con libertad y responsabilidad en un mundo que puede y debe ser cada vez más diverso, en el que cada cual se sepa dueño de su biografía sexual y amorosa. (F. López, comunicación personal, 15 de abril de 2015) 
f. Desde otro plano, se definen buenas prácticas como los diversos cursos, talleres, congresos, que algunos sectores de la sociedad (universidades estatales, ONG, y Asociaciones pro derechos humanos, entre otros) han desarrollado, y que desde una visión de justicia social y sexualidad se han venido efectuando en la última década. Sin duda alguna, este tipo de acciones inciden en sectores importantes de profesionales y miembros de la comunidad social, que tienen a cargo actuaciones al respecto. En este aspecto, un paso importante sería contar con mayor apoyo del Estado, instituciones y empresas, para lograr que los costos, en su realización, puedan ser de mayor accesibilidad para la comunidad en general, incluso que se pudiera brindar este tipo de estrategias a la comunidad, por ejemplo, congresos dirigidos a madres y padres de familias, docentes, empleadas y empleados públicos, colectivos "minoritarios", niñez, clase política de las comunidades o gobiernos municipales, etc. Y, por otro lado, se requiere el apoyo y compromiso de los medios de comunicación masiva, con el fin de que lleven la información al pueblo, que vuelvan su interés a aquellos temas que fortalecen la justicia social en una nación y no tengan prioridad los titulares amarillistas.

Dentro de este boceto de buenas prácticas se incluyen las realizadas por diversas instituciones, organizaciones o asociaciones (Fundación Ciudadelas de Libertad, en Desamparados; Asociación Raht; Instituto WEE; Hogar Esperanza; Asociación Universitaria Pro Educación Indígena; grupos prodefensa de los derechos de la comunidad LGBT, etc.) que nacieron desde un profundo respeto por la dignidad humana, que de forma (en algunos casos) muchas veces clandestina, abordan un fenómeno social (muchas veces no asumido por el Estado), y realizan acciones de educación, fortalecimiento humano, para devolver esa "dignidad humana", en muchos casos violentada por la injusticia estructural, social, económica, política, sexual, entre otras.

Igualmente, podemos citar aquellas que desde el derecho a la manifestación se desarrollan en nuestras calles o plazas, a manera de marchas, caminatas o celebraciones, etc. En estas, el sector social señala al colectivo político sus exigencias y recuerda las obligaciones que como políticos o políticas, legisladores o legisladores y personal empleado público tienen en torno a la justicia social y la sexualidad; por otro lado, 
resulta una estrategia de información al pueblo sobre realidades, necesidades y demandas que deben ser respetadas.

Otra buena práctica (de impacto en una sociedad como la costarricense) relacionada con los derechos de las personas homosexuales o lesbianas, entre otras, en general con las personas sexualmente diversas) es el denominado "Beso diverso" que, según María Isabel Vitoria planteó en la entrevista, nació producto de una experiencia de discriminación, cuando en un bar capitalino se le negó la atención y se le pidió que abandonara el local a una pareja de mujeres lesbianas en el año 2007. De tal experiencia, un grupo de ciudadanas se organizaron y fundaron la Coordinación del Beso Diverso, una iniciativa LGBTI liderada por mujeres jóvenes, cuyo "objetivo va dirigido a la promoción de organización y movilización, activismo político a favor de los derechos de personas sexualmente diversas" (M. I. Vitoria, comunicación personal, 12 de mayo del 2015).

Desde un nivel más particularizado y personal, otra buena práctica es la que usted, nosotras y nosotros, cada quien, desde el seno de nuestro hogar o trabajo realizamos en pro de la justicia social e igualdad de oportunidades, cuando respetamos y vivenciamos con la otredad de la otra persona, el respeto a su diferencia que igualmente es la nuestra. Cuando no sale de nuestras bocas, un chiste homófobo, un comentario xenofóbico, sexista o machista. Y es ahí, en los pequeños espacios relacionales donde la sociedad cambia, donde el concepto de ser humano llega a su perfección en dignidad y derecho.

Buenas prácticas, como la de aquella abuela en medio de la capital con su nieto, que al escuchar la pregunta de su nieto: ¿Por qué a mi tío, le gusta otro hombre? Ella responde "amor mío, la capacidad de los seres humanos es tan grande que nos permite amarnos entre personas del mismo sexo, y ahora lo que tenemos que aprender es a respetar ese amor". O aquella madre de familia, que haciendo alusión a una pregunta de su hijo, sobre la igualdad entre hombres y mujeres, "el trato desigual, no es más que el producto de la ignorancia, por eso debes estudiar y ser un ser humano noble, equitativo y respetuoso".

Como podemos visualizar, existen buenas prácticas por realizar en los diversos órdenes, todas de una u otra manera importantes, que buscan desarrollar mayores espacios de sensibilización, información, aprendizaje y formación, en torno perspectivas de promoción de la igualdad en materia de justicia social dentro, del ámbito sexual y 
su educación afectiva y sexual. Queda claro que el compromiso es de todos y todas en busca de una sociedad proactiva en sus procesos de desarrollo de justicia social con dignidad.

\section{Conclusiones}

A manera de conclusión, algunas de las ideas principales dentro de este reflexionar son:

La justicia social para una vivencia afectiva y sexual constituye un proceso complejo y dinámico, donde confluye una diversidad de factores de índole política, económica, social, cultural, religiosa, espiritual, entre otras. Ambos términos, justicia social y sexualidad, son conceptos que se van transformando por sí mismos y, a su vez, entre sí, de manera que sería irrisoria la idea de pensar que son conceptos finitos y terminados: pensar de esta manera seria afirmar que la misma humanidad y, por ende, la sociedad, donde toman vida dichos conceptos, no evoluciona y se mantiene inmóvil al cambio, es decir, al estancamiento del desarrollo social.

Todo indica que, si bien las sociedades del mundo han crecido en legislación y ejecución de la justicia social, aún falta mucho que hacer en lo referente a justicia social para una vivencia afectiva y sexual. Pareciera que, a nivel general, existen avances, pero es en la minuciosidad de las acciones y vivencias de la historia de vida de las personas, donde se visualiza la falta de una mayor justicia en igualdad y equidad entre los seres humanos y en especial en materia de sexualidad. Se requiere una sociedad con mayor educación inclusiva, donde el valor de la diferencia sea comprendido y respetado, una educación que permita alejarse cada día más de una cultura patriarcal, sexista, normalista y machista; elementos que han sustentado en los sistemas patriarcales y conservadores el ejercicio de la ignorancia, el miedo a lo nuevo, la inflexibilidad, el irrespeto a la persona (biografías sexuales diferentes) y actitudes negativas y erotofílicas de la sexualidad. Una educación enmarcada en un proceso que permita la aproximación al desarrollo humano sostenible, con la clara conciencia y determinación que es un trabajo que atañe a toda persona, no importa su condición social, económica o personal.

La sociedad que genere una justicia social que facilite la promoción de una vivencia afectiva y sexual requiere, sin duda alguna, cultivar y fortalecer el conocimiento científico de sus habitantes, libre 
de cualquier amago de sesgo, duda o imposición ideológica, particularmente en materia de sexualidad humana, la cual contiene, dentro de su misma dinámica, una rica diversidad.

Unido a lo anterior, se requiere que la sociedad se dé a la tarea de fortalecer la justicia social para la promoción afectiva y sexual, no responda a ninguna ideología religiosa, o moral religiosa. No discutimos el papel de las iglesias, pero en una sociedad democrática, se debe responder a todas las personas, y nunca desde el pensar de un grupo u otro; sobre todo en materia de la sexualidad y su vivencia, estamos hablando de la necesidad de un Estado secular, pero respetuoso de la libertad religiosa. Por otra parte, pero en relación con lo expresado, una sociedad con justicia social para la promoción afectiva y sexual debe incidir en la fomento de las libertades básicas, dentro del marco de la sexualidad, y desde un enfoque de actitudes positivas hacia sexualidad y su educación, en un ámbito de la ética relacional (Fallas, 2010; López, 2005 y Torres et al., 2013).

Para finalizar, es importante dar reconocimiento a todas aquellas prácticas, que desde la visión pública, hacen esfuerzos en pro de la justicia social en el campo de la sexualidad; pero también a aquellas otras, algunas desde la clandestinidad diaria de la vivencia cotidiana de las personas, que permiten que una sociedad como esta vaya dando pasos al desarrollo en justicia social sexual. Si bien son necesarias las grandes acciones dentro de la organización política y demás, es por medio de la educación formal y no formal, como se construye una nueva dimensión relacional que, sin temor a hacerle frente a los mandatos de una cultura patriarcal, logre, desde las propias simientes de las estructuras, dar un paso para aprender con amor a abrazar nuestra propia diferencia y la diferencia del otro individuo, con una calidez respetuosa que incida en el ansiado desarrollo humano en todos sus niveles y expresiones.

\section{Referencias}

Barrantes, B. (15 de junio del 2012). Costa Rica mantiene su discurso cargado de mitos sobre sexualidad. Madres adolescentes encarnan historias de exclusión y rechazo. La Nación Aldea Global. Recuperado de http://www.nacion.com/2012-06-15/AldeaGlobal/Madres-adolescentes-encarnan - 
Benavides, L. (Enero-marzo, 2008). Más allá del concepto: Desarrollo sostenible. Tecnología en Marcha, 21(1), pp. 133-140

Cruz, I. (s. f.). Desarrollo humano sostenible. Recuperado de http://portalsostenibilidad.upc.edu/detall_01.php?id=208\&numapartat $=0$

Decreto Política para la Erradicar de las Instituciones Públicas la Discriminación hacia la Población Sexualmente Diversa en su Directriz $\mathrm{N}^{\circ}$ 025P. Gaceta, 2015, $\mathrm{N}^{\circ}$ 103. Diario oficial del Gobierno de Costa Rica. Recuperado de http://www.gaceta.go.cr/ pub/2015/05/29/COMP_29_05_2015.pdf

Fallas-Vargas, M. (2010). Educación afectiva y sexual. Programa de formación docente de secundaria (Tesis doctoral). Salamanca: Universidad de Salamanca.

La Nación. El país. (15 de marzo del 2013). Justo Orozco y la defensora debate sobre discriminación a homosexuales y fecundación in vitro. Recuperado de http://www.nacion.com/2012-05-30/ElPais/ Texto-completo--Justo-Orozco-y-defensora-debaten-sobre-discriminacion-a-homosexuales-y-fecundacion-in-vitro.aspx/

López, F. (2005). La educación sexual. Madrid: Biblioteca nueva.

Mata, A. (21 de febrero del 2010). Crece desventaja salarial de las mujeres frente a los hombres. La Nación.com/el país. Recuperado de $\mathrm{http} / / / w v w . n a c i o n . c o m / / n \_e e / 2010 /$ febrero/21/pais2275771.html

Molina, B., Yamuni, M. y Villalobos, A. (24 de enero del 2013). Una ley para regular la fecundación in vitro. La Nación Opinión. Recuperado de http:/www.nacion.com/2013-01-24/Opinion/ una-ley-para-regular-la-fecundacion-in-vitro.aspx

Murillo, F., Román, M. y Hernández, R. (2011). Educación educativa para la justicia social Revista Iberoamericana de Evaluación Educativa, 4(1), pp.7-23.

Murillo, J., Krichesky, G., Castro, A. y Hernandes, R. (2010). Liderazgo para la inclusión escolar y la justicia social. Aportaciones de la investigación. Revista Latinoamericana de inclusión educativa, 4(1), 169-186. Recuperado de http://www.rinace.net/rlei/numeros/vol4-num1/art8.pdf

Torres, N, Cerdas, V. y García, J. (2013). Equidad y justicia social. Un reto para el liderazgo pedagógico. Heredia, Costa Rica: URUK.

Organización Panamericana de la Salud, Organización Mundial de la Salud. (2000). Promoción salud. Recomendaciones para la acción. Actas de una reunión de consulta convocada por Organización 
Mundial de la Salud (OMS). En colaboración con la Asociación Mundial de Sexología (WAS). Celebrada en Antigua Guatemala, 19 al 22 de mayo.

Organización Internacional del Trabajo. (Febrero, 2011). La organización internacional del trabajo y la justicia social. Suiza. Recuperado de (http://www.ilo.org/wcmsp5/groups/public/---dgreports/---dcomm/documents/publication/wcms_151881.pdf

Ruiz, E. y Estrevel, L. (2010). Vigotsky: La escuela y la subjetividad. Pensamiento Psicológico, 8(15), 135 a195.

Soto, J. (22 de enero del 2013a). Diputados sin ánimo para discutir proyecto de sociedades de convivencia. Crhoy.com noticias 24/7. Recuperado de http://www.crhoy.com/diputados-sin-animo-para-discutir-proyectos-de-sociedades-de-convivencia/

Soto, J. (13 de marzo del 2013b). Ejecutivo desconvoca proyecto de sociedades de convivencia. Recuperado de http://www.crhoy.com/ ejecutivo-desconvoca-proyecto-de-sociedades-de-convivencia/

Soto, W. (octubre, s. f.). La "otredad del otro" y el cosmopolitismo como ejes transversales en los procesos de enseñanza-aprendizaje en las Ciencias Sociales. Ponencia durante la semana de Ciencias Sociales de la Universidad Nacional.

Word Association for Sexology. (1999). Declaración de los derechos sexuales. Versión revisada y aprobada por la Asamblea General de la Asocicación Mundial de Sexología, celebrada en Hong Kong, Republica de China. Recuperada de htt//www.wordsexology/about_sexualrights_spanish.asp. 